\title{
The Interplay Between Pituitary Health and Diabetes Mellitus - The Need for 'Hypophyseo-vigilance'
}

\author{
Saptarshi Bhattacharya, ${ }^{1}$ Sanjay Kalra, ${ }^{2}$ Deep Dutta, ${ }^{3}$ Deepak Khandelwal ${ }^{4}$ and Rajiv Singla ${ }^{5}$ \\ 1. Max Super Speciality Hospital, Patparganj, New Delhi, India; 2. Bharti Hospital, Karnal, India; 3. Cedar Superspeciality Clinics, Dwarka, New Delhi, India; \\ 4. Maharaja Agrasen Hospital, New Delhi, India; 5. Kalpvrisksh Clinic, New Delhi, India
}

DOI: https://doi.org/10.17925/EE.2020.16.1.25

$\mathrm{T}$ he anterior and posterior hypophyseal hormones alter glucose metabolism in health and disease. Secondary diabetes may occur due to the hypersecretion of anterior pituitary hormones like adrenocorticotrophic hormone in Cushing's disease and growth hormone in acromegaly. Other hormones like prolactin, gonadotropins, oxytocin and vasopressin, though not overtly associated with causation of diabetes, have an important physiological role in maintaining glucose homeostasis. Hypoglycaemia is not an unusual occurrence in hypopituitarism. Many of the medications that are used for the treatment of hypophyseal diseases alter glucose metabolism. Agents like pasireotide should be used with caution in the setting of diabetes, whereas pegvisomant should be given preference. Diabetes mellitus itself, on the other hand, can alter the functioning of the hypothalamic pituitary axis; this is documented in both type 1 and type 2 diabetes. This review focuses on the clinically relevant interplay of hypophyseal hormones and glucose homeostasis. The authors define 'hypophyseo-vigilance' as an approach which keeps the bidirectional, multifaceted interactions between the pituitary and glucose metabolism in mind while managing diabetes and pituitary disease.

\section{Keywords}

Diabetes mellitus, pituitary, hypophysis, acromegaly, Cushing's disease, hypogonadism

Disclosures: Saptarshi Bhattacharya, Sanjay Kalra Deep Dutta, Deepak Khandelwal and Rajiv Singla have no financial or non-financial relationships or activities to declare in relation to this article. Sanjay Kalra is a member of the journal's Editorial Board.

Review Process: Double-blind peer review.

Compliance with Ethics: This article involves a review of the literature and does not report on new clinical data, or any studies with human or animal subjects performed by any of the authors.

Authorship: All named authors meet the criteria of the International Committee of Medical Journal Editors for authorship for this manuscript, take responsibility for the integrity of the work as a whole and have given final approval for the version to be published.

Access: This article is freely accessible at

touchENDOCRINOLOGY.com (c) Touch Medical Media 2020.

Received: 20 August 2019

Accepted: 12 September 2019

Published Online: 18 October 2019

Citation: European Endocrinology. 2020;16(1):25-31

Corresponding Author: Saptarshi Bhattacharya,

Max Super Speciality Hospital, 108A IP Extension,

Patparganj, Delhi, 110092, India. E: saptarshi5@yahoo.com

Support: No funding was received in

the publication of this article.
The pituitary gland, or hypophysis, is the 'master gland' that secretes multiple hormones which regulate the functioning of other endocrine organs, such as the thyroid, adrenal cortex and gonads. Though none of the major pituitary hormones directly control the endocrine glandular components of the pancreas, there are multiple indirect interactions that alter glucose homeostasis. Bromocriptine quick-release formulation, an agent used for the treatment of hyperprolactinemia, is also approved for treatment of type 2 diabetes mellitus (T2DM). Though not a very popular therapeutic choice for diabetes mellitus (DM) management, the drug does, however, open the window of possibility that hypophyseal hormones and other neurotransmitters can turn out to be novel therapeutic strategies to treat DM. DM, on the other hand, has been recognised as a common cause behind the development of hypophyseal disorders like hypogonadotropic hypogonadism $(\mathrm{HH}) .^{1,2}$ Thus, pituitary disease can cause hypoglycaemia or hyperglycaemia, and conversely dysglycaemia can also alter pituitary function. The pituitary gland shares a multifaceted relationship with glucose metabolism. The focus of this review is to help the clinician understand and recognise these various interactions. The concept of hypophyseo-vigilance aims to encourage the clinical suspicion of pituitary disease in dysglycaemia and help recognise pituitary dysfunction in the setting of altered glucose metabolism in a timely manner. It is hoped that this will help to improve medical care and optimise clinical outcomes.

\section{Glucose metabolism in anterior pituitary disease}

Anterior pituitary dysfunction can be due to either hypersecretion or hyposecretion of pituitary hormones. The impact of anterior pituitary dysfunction on glucose metabolism has been described in Table 1.

\section{Hyperfunction}

This encompasses four recognised conditions of hormone hypersecretion: growth hormone (GH)-secreting pituitary adenoma, or acromegaly; adrenocorticotropic hormone (ACTH)-secreting pituitary adenoma, or Cushing's disease; prolactin-secreting pituitary adenoma; and very rarely, thyroid-stimulating hormone (TSH)-secreting pituitary adenoma. Gonadotrophin-secreting adenomas are usually clinically non-functioning, but secretion of intact follicle-stimulating hormone (FSH) in women of reproductive age has been associated with ovarian hyperstimulation. ${ }^{3}$

\section{Growth hormone hypersecretion}

In a database of 3,173 patients recently diagnosed with acromegaly, prevalence of DM was $27 \%$. In the same study in subjects without diabetes, the glucose levels correlated with insulin-like growth factor-1 (IGF-1) levels, but not with GH levels. ${ }^{4} \mathrm{GH}$ enhances hepatic glucose production by opposing 
Table 1: Glucose metabolism in anterior pituitary dysfunction

\begin{tabular}{|c|c|}
\hline Disease/condition & Effect on glucose metabolism \\
\hline \multicolumn{2}{|c|}{ Anterior pituitary hypersecretory conditions } \\
\hline GH hypersecretion & $\begin{array}{l}\text { Insulin resistance } \\
\text { Diabetes mellitus }\end{array}$ \\
\hline ACTH hypersecretion & $\begin{array}{l}\text { Impaired glucose tolerance } \\
\text { Diabetes mellitus }\end{array}$ \\
\hline Prolactin hypersecretion & $\begin{array}{l}\text { Prolactinoma - higher FPG in small studies } \\
\text { Physiological hyperprolactinaemia - insulin } \\
\text { resistance? }\end{array}$ \\
\hline TSH hypersecretion & Insulin resistance, worsening of diabetes \\
\hline \multicolumn{2}{|c|}{ Anterior pituitary hyposecretory conditions } \\
\hline Panhypopituitarism & Hypoglycaemia \\
\hline GH deficiency & $\begin{array}{l}\text { Children - insulin sensitivity, fasting } \\
\text { hypoglycaemia } \\
\text { Adults - insulin resistance }\end{array}$ \\
\hline $\begin{array}{l}\text { Functional hypogonadotropic } \\
\text { hypogonadism }\end{array}$ & $\begin{array}{l}\text { Insulin resistance, impaired glucose tolerance, } \\
\text { higher visceral adipose tissue, adverse } \\
\text { cardiovascular outcome }\end{array}$ \\
\hline
\end{tabular}

ACTH = adrenocorticotrophic hormone; $F P G$ = fasting plasma glucose; $\mathrm{GH}=$ growth hormone; $\mathrm{TSH}=$ thyroid-stimulating hormone.

the action of insulin on the liver and stimulates gluconeogenesis. $\mathrm{GH}$ also increases hepatic and peripheral insulin resistance. One of the mechanisms behind peripheral insulin resistance is substrate competition with glucose due to higher free fatty acid availability from GH-induced lipolysis. On the other hand, IGF-1 improves peripheral insulin sensitivity but is not enough to override the diabetogenic action of chronic GH excess. ${ }^{5}$ Studies have demonstrated the association of IGF-1 levels and DM as predictors of mortality in acromegaly. ${ }^{6,7}$

\section{Adrenocorticotrophic hormone hypersecretion}

Cushing's disease, or ACTH-secreting pituitary adenoma, is another recognised cause of DM. ${ }^{8}$ The prevalence of DM in Cushing's disease is 40-45\%, and an additional 10-30\% have impaired glucose tolerance. ${ }^{9.10}$ A state of chronic cortisol excess stimulates hepatic gluconeogenesis partly resulting from increased mobilisation of gluconeogenic substrate from peripheral tissues. Cortisol also has a permissive effect on glucagon and epinephrine in inducing gluconeogenesis and glycogenolysis. Insulin secretory defects coupled with increased peripheral insulin resistance have an additional role in the development of hyperglycaemia. ${ }^{9}$

\section{Prolactin hypersecretion}

Unlike acromegaly and Cushing's disease, hyperprolactinaemia is not a recognised cause of DM. ${ }^{11}$ Small studies have demonstrated that prolactinoma is associated with higher fasting plasma glucose (FPG) that can be corrected with treatment with cabergoline. ${ }^{12,13}$ However, the relationship between DM and prolactin is complex. In a population-based study of 2,377 Chinese men and postmenopausal women, elevated serum prolactin levels were associated with lower prevalence of DM. ${ }^{14}$ In another population-based study of 370 Japanese men without diabetes, elevated prolactin in the physiological range showed an association with insulin resistance. ${ }^{15}$ Experimental studies also show conflicting results. ${ }^{16-9}$ On the one hand, prolactin has been shown to induce beta-cell growth in the pancreas, ${ }^{16,17}$ while on the other hand, prolactin is also hypothesised to increase insulin resistance by blocking adiponectin and interleukin (IL)-6 production in fat cells. ${ }^{18,19}$

\section{Others}

Thyrotoxicosis can cause insulin resistance and predispose to diabetes. ${ }^{20}$ TSH secreting pituitary adenoma by producing thyrotoxicosis can worsen glucose intolerance like in any other thyrotoxic state, but the condition is very rare and to our knowledge, diabetes arising from this condition has not been reported. ${ }^{21}$ Gonadotropin-secreting tumours are non-functional; only in exceptional circumstances they can produce manifestations related to gonadotropin excess, which is not usually linked to glucose homeostasis.

\section{Hypofunction}

Pituitary hypofunction or hypopituitarism implies the deficiency of one or more anterior and posterior pituitary hormones. The common causes of hypopituitarism are pituitary adenoma or other sellar and suprasellar lesions, surgery or radiation to the pituitary gland, traumatic brain injury, and Sheehan's syndrome. In most of these situations, multiple hormones are deficient; however, in lymphocytic hypophysitis, isolated deficiency of a single hormone can occur. Hypoglycaemia can be a presenting feature of hypopituitarism..$^{22}$ It results primarily from hypocortisolism, secondary to defect in ACTH secretion coupled with deficiency of GH.

GH deficiency has a different impact on glucose homeostasis at various stages of life. Children with GH deficiency have a tendency to be insulin sensitive and can develop spontaneous fasting hypoglycaemia due to reduced hepatic glucose production. ${ }^{23} \mathrm{GH}$-deficient adults who are not receiving $\mathrm{GH}$ substitution, however, are insulin resistant. ${ }^{24}$

Besides overt hormonal deficiency, functional hypogonadism, presumed to be due to a non-organic defect in the hypothalamic-pituitary-testicular axis, is a common cause of low plasma testosterone in adult males with comorbidities like diabetes and obesity. ${ }^{25}$ Low plasma total testosterone levels have been linked with insulin resistance, impaired glucose tolerance, higher visceral adipose tissue and adverse cardiovascular (CV) outcomes. ${ }^{26,27}$ Whether metabolic syndrome is the cause behind hypogonadism or its effect remains an area of controversy. ${ }^{28}$

\section{Glucose metabolism in posterior pituitary disease}

The posterior pituitary secretes two major hormones - oxytocin and vasopressin.

\section{Oxytocin}

An imbalance in oxytocin secretion related to a disease process is not known to cause any specific defect in glucose metabolism; however, over the last few years the physiological role of oxytocin in glucose and lipid metabolism has been recognised. Peripherally, oxytocin maintains electrolyte balance, glucose metabolism and adipogenesis, and centrally it is involved in food selection, reward and satiety. ${ }^{29}$ Oxytocin preferentially suppresses intake of sweet-tasting carbohydrates. Animal studies indicate that defects in oxytocin signalling and receptor expression can lead to weight gain despite normal food intake. ${ }^{30}$ Oxytocin levels were found to be lower in individuals with newly diagnosed T2DM or who were obese..$^{31} \mathrm{~A}$ review analysing the weight-lowering and glycaemic benefits of intranasal oxytocin in a few small studies showed a positive trend. ${ }^{32}$

\section{Vasopressin}

Two conditions, diabetes insipidus, a condition caused by vasopressin or antidiuretic hormone (ADH) deficiency, and syndrome of inappropriate ADH (SIADH), whereby ADH is secreted in excess, do not have any direct effect on glucose metabolism. However, other than its role in fluid balance, there is emerging evidence that vasopressin influences 
Table 2: Glucose metabolism during treatment with drugs used for pituitary dysfunction

\begin{tabular}{|l|l|}
\hline Drug/condition & Effect on glucose metabolism \\
\hline $\begin{array}{l}\text { GH-replacement } \\
\text { therapy }\end{array}$ & $\begin{array}{l}\text { Children - subtle insulin resistance, new onset DM rare; } \\
\text { Adults - association with impaired glucose tolerance and } \\
\text { DM in initial years, prolonged therapy - improvement } \\
\text { in metabolic parameters and decreased CVD risk }\end{array}$ \\
\hline $\begin{array}{l}\text { Octreotide and } \\
\text { lanreotide }\end{array}$ & $\begin{array}{l}\text { Postprandial hyperglycaemia and increase in HbA1c } \\
\text { in uncontrolled disease; } \\
\text { If disease is under control - neutral or mild improvement } \\
\text { in glycaemic indices }\end{array}$ \\
\hline Pasireotide & New onset DM, uncontrolled hyperglycaemia \\
\hline Pegvisomant & Improvement in glycaemic status \\
\hline Bromocriptine & Quick-release formulation approved for treatment of DM \\
\hline Cabergoline & Anecdotal reports of glycaemic and weight benefit \\
\hline GnRH analogue & $\begin{array}{l}\text { Increased chance of diabetes, more in males on androgen } \\
\text { deprivation therapy }\end{array}$ \\
\hline Mifepristone & $\begin{array}{l}\text { Approved for treatment of hyperglycaemia in } \\
\text { Cushing's syndrome }\end{array}$ \\
\hline Mecasermin & \begin{tabular}{l} 
Adverse effect of hypoglycaemia, must be taken with food \\
\hline
\end{tabular} \\
\hline
\end{tabular}

$C V D=$ cardiovascular disease; $D M=$ diabetes mellitus; $G H$ = growth hormone;

$\mathrm{GnRH}=$ gonadotropin-releasing hormone; $H$ bA1C = glycated haemoglobin .

glucose metabolism. Murine and in vitro studies have demonstrated that the vasopressin receptor $\mathrm{V} 1 \mathrm{a}$ is present in the liver where its activation causes glycogenolysis and gluconeogenesis. ${ }^{33,34}$ The pancreas also expresses V1b receptors on both alpha and beta cells. At higher glucose concentration, vasopressin predominantly causes insulin secretion from beta cells, whereas at lower glucose concentration it primarily releases glucagon from alpha cells. ${ }^{35}$

Murine studies demonstrate that vasopressin has a predominant role in inducing insulin resistance and causing hyperglycaemia through activation of the V1a receptor. ${ }^{36,37}$ These animal data have been corroborated through clinical studies that indicate that high vasopressin levels can be a risk factor for DM..$^{38,39}$ Copeptin, the C-terminal of the pre/pro-vasopressin peptide, has been used as a surrogate indicator of vasopressin in clinical studies because it is stable and can be assayed easily. ${ }^{40} \mathrm{~A}$ recent review summarises the experimental evidence, as well as the human studies, mostly epidemiological, that have demonstrated that high copeptin levels are associated with DM, insulin resistance, obesity, hypertension and metabolic syndrome. ${ }^{41}$ An interesting study which further corroborates the relationship of vasopressin with hyperglycaemia showed that higher water intake (which in turn will lower vasopressin level) was associated with a lower chance of new-onset hyperglycaemia. ${ }^{42}$

\section{Alteration in glucose metabolism with drugs used for the treatment of pituitary dysfunction}

Many of the drugs that are used for the treatment of pituitary dysfunction have an impact on glucose metabolism (Table 2). The clinical recommendations for the screening and treatment of dysglycaemia during the management of pituitary hyperfunction and hypofunction with these medications are summarised in Tables 3 and 4 , respectively.

\section{Growth hormone replacement therapy}

GH replacement alters insulin sensitivity in a complex fashion. In a recently published review, the authors found that in the majority of studies, GH treatment in children resulted in a subtle form of insulin resistance,
Table 3: Practical considerations for the management of glycaemic parameters in pituitary hypersecretory states

Screen for DM by measuring FPG, OGTT or HbA1c in acromegaly, Cushing's disease and TSH-secreting pituitary adenoma

First generation SSA is the first-line therapy for acromegaly with persistent disease despite surgical resection

Pegvisomant should be the preferred switch-over agent in patients not optimally controlled on first-generation SSAs, in the presence of pre-existing clinically relevant impaired glucose metabolism

First-generation SSAs increase HbA1c by causing postprandial hyperglycaemia; appropriate adjustment in glucose-lowering treatment is recommended

Second-generation SSAs, like pasireotide, worsen glycaemic status; treatment with incretin-based or other glucose-lowering therapy to be considered. In case of severe hyperglycaemia, switch over to pegvisomant is recommended

For Cushing's disease not cured by surgical treatment, use of pasireotide can worsen glucose metabolism; incretin-based or other glucose-lowering therapy to be considered

Treatment with mifepristone can improve hyperglycaemia in Cushing's syndrome

$D M=$ diabetes mellitus; $F P G=$ fasting plasma glucose; $H D A 1 C=$ glycated haemoglobin OGTT = oral g/ucose tolerance test $;$ SSA = somatostatin analogue $\mathrm{TSH}=$ thyroid-stimulating hormone.

Table 4: Practical considerations for the management of glycaemic parameters in pituitary hyposecretory states

Hypoglycaemia can be a manifestation of panhypopituitarism; children with $\mathrm{GH}$ deficiency have fasting hypoglycaemia. Appropriate screening should be considered in relevant situations

Hypogonadotropic hypogonadism and adult GH deficiency are associated with insulin resistance. Screen for DM when appropriate

Glucocorticoid replacement therapy can induce hyperglycaemia, with the characteristic pattern of an afternoon or evening rise in plasma glucose. Consider short-acting insulin prior to lunch

Hypoglycaemia is a recognised adverse effect of mecasermin. Appropriate precautions are advocated, including administration with food

$D M=$ diabetes mellitus; $G H=$ growth hormone.

though FPG and glycated haemoglobin (HbA1c) mostly remained in the normal range. ${ }^{43}$ New onset T2DM rarely occurs during GH treatment in children with GH deficiency or even with idiopathic short stature. ${ }^{44}$ Those with Turner syndrome and children who are small for gestational age, have a higher lifetime chance of developing T2DM compared with the background population, but GH therapy in such children does not alter the incidence of T2DM in short term. ${ }^{45}$

In adults with a higher BMI and/or family history of T2DM, GH therapy can be associated with the development of glucose intolerance or T2DM in the initial years of treatment, though the incidence decreases with prolonged treatment. ${ }^{46,47}$ Close monitoring of glycaemic status is advisable for adults with risk factors for T2DM on GH replacement. ${ }^{45}$ Treatment of GH deficiency in adults decreases fat mass and improves lean body mass, lipid profile, carotid intima medial thickness, and CV inflammatory markers, and more than offsets for mild derangement in glycaemic parameters. ${ }^{48-50}$

\section{First-generation somatostatin analogues}

octreotide and lanreotide are considered as first-generation somatostatin analogues (SSAS) having a strong affinity to somatostatin receptor 2 (SSR2) and SSR5, and a weaker affinity to SSR3. They are the first-line 
medical therapy for acromegaly. First-generation SSAs exert a glucose-lowering effect by decreasing $\mathrm{GH}$ secretion from the tumour, which is counterbalanced by its action on the pancreas where somatostatin and its analogues inhibit insulin secretion. ${ }^{51}$ The net effect on glucose metabolism in acromegaly is variable. In a recently published meta-analysis, the authors showed that a mild but significant increase in HbA1c occurred with first-generation SSAs, resulting from an increase in post-prandial glucose levels without any alteration in FPG. It was also demonstrated that first-generation SSAs significantly reduced insulin secretion which was not completely counterbalanced by the reduction in GH and IGF-I levels. The authors concluded that the overall effect of first-generation SSAS on glucose metabolism depends on the net balance between these two opposing factors and on the patient's predisposition. ${ }^{52}$ Different trends were observed in a retrospective 1-year study comparing SSAS to surgery. SSAs caused improvement in all metabolic syndrome parameters and significantly lowered FPG and HDA1C when the disease activity was controlled, the main determinant of glycaemic improvement. ${ }^{53}$ Higher dose and higher frequency of SSAs do not have an unfavourable glycaemic impact. ${ }^{54,55}$ To summarise, octreotide and lanreotide might have a mild detrimental effect on post-prandial hyperglycaemia and $\mathrm{HbA} 1 \mathrm{C}$, especially in the setting of uncontrolled disease activity. If the disease is under control, first-generation SSAs have either a neutral or even a slightly beneficial effect on glycaemic indices.

\section{Pasireotide}

This novel SSA has strong affinity for SSR5 and SSR1, moderate affinity for SSR3 and lower affinity for SSR2 in comparison to octreotide. ${ }^{56}$ In addition to better efficacy for the treatment of acromegaly as compared with first-generation SSAS, pasireotide, by virtue of its affinity for both SSR2 and SSR5, suppress ACTH hypersecretion in patients with corticotroph tumours. ${ }^{57,58}$ Its predominant adverse effect is hyperglycaemia in both acromegaly (57.3-67.0\%) and Cushing's disease (68.4-73.0\%), and uncontrolled hyperglycaemia is a common cause of treatment discontinuation. ${ }^{59}$ Insulin release from beta cells of islets of Langerhans is mediated by SSR5 and SSR2, and glucagon release from alpha cells depends on SSR2. ${ }^{60}$ Pasireotide has a prominent inhibitory effect on insulin release as a result of its higher affinity for SSR5, whereas the inhibitory effect on glucagon secretion due to SSR2 affinity is only modest. First-generation SSAS are more potent suppressors of glucagon secretion because of stronger binding to SSR2.. ${ }^{61}$ Apart from this imbalance in insulin and glucagon secretion, pasireotide also reduces incretin response, and incretin-based therapy might be more effective than other forms of therapy for the management of hyperglycaemia in this condition. ${ }^{62}$

\footnotetext{
Pegvisomant

Pegvisomant is a genetically engineered potent $\mathrm{GH}$ receptor antagonist that acts at the receptor level to decrease IGF-1 levels. ${ }^{33}$ Unlike SSAS, it does not have any inhibitory action on insulin secretion on the pancreas, but it does have a favourable effect on glycaemic status. ${ }^{64}$ Pegvisomant improves glucose metabolism by improving insulin resistance in acromegaly through the blocking of excess GH action. ${ }^{65,66}$ It has a positive impact on glycaemic control in patients with acromegaly and uncontrolled DM. ${ }^{67}$ Patients with acromegaly and DM have a higher requirement for pegvisomant to control the disease and have a lower rate of IGF-1 normalisation compared to those without DM..$^{68} \mathrm{~A}$ possible hypothesis is that hepatic GH receptor expression may be increased due to hyperinsulinism and a higher dose of pegvisomant may be needed to saturate it. ${ }^{69}$ The recently published consensus statement by Melmed et al. recommends shifting from first-generation SSAs to pegvisomant in case there is pre-existing clinically relevant impaired glucose metabolism. ${ }^{70}$
}

\section{Bromocriptine}

Dopamine and dopaminergic signals in the central nervous system (CNS) decrease liver gluconeogenesis via the sympathetic nervous system. In obese individuals with DM, decreased dopaminergic activity alters signalling from the CNS, resulting in increased hepatic gluconeogenesis and insulin resistance. ${ }^{11}$ Antipsychotic medicines that block dopaminergic activity cause weight gain, dyslipidaemia and insulin resistance. ${ }^{72}$ Bromocriptine, a D2-dopamine agonist with sympatholytic activity, is primarily indicated for the treatment of prolactinoma. Bromocriptine quick-release tablet ingestion within 2 hours of waking is assumed to enhance low hypothalamic dopamine levels and inhibit excessive sympathetic tone within the $\mathrm{CNS}^{73}$ This is the only approved glucose-lowering medication that predominantly acts on the CNS and causes reduction of FPG, HbA1C, triglyceride and free fatty acid levels. ${ }^{74}$ In a 1-year prospective study, HbA1C was decreased by $0.6 \%$ and composite CV outcome was reduced by $40 \%{ }^{75}$ However, the mechanism behind reduction in $\mathrm{CV}$ events is not defined. The additional advantages of bromocriptine include absence of hypoglycaemia, no change in weight and lack of major side effects.

\section{Cabergoline}

Cabergoline, a long-acting D2-dopamine agonist, is better tolerated than bromocriptine and is considered as the first-line treatment of hyperprolactinaemia. It also has demonstrated benefit in DM, obesity and insulin resistance in small studies. ${ }^{76-8}$ In a recently published trial, cabergoline did not exhibit any difference to placebo in maintaining weight loss in obese subjects who had lost at least $5 \%$ weight with an $800 \mathrm{kcal} /$ day commercial meal replacement programme. ${ }^{79}$ Cabergoline, despite being a stronger D2 receptor agonist, has minimal glycaemic benefit compared with bromocriptine quick-release formulation. The unravelling of the intricacies of dopaminergic and other CNS pathways that control metabolism might resolve these discrepancies in the future.

\section{Gonadotropin-releasing hormone analogue}

Gonadotropin-releasing hormone (GnRH) analogues, such as leuprolide, triptorelin, buserelin, goserelin and histrelin, are used in adult females for the treatment of endometriosis, fibroids, premenopausal ovarian suppression, and for the treatment of metastatic prostate cancer in males. The metabolic changes that occur due to androgen-deprivation therapy with GnRH analogues in males include an increase in adipose tissue, increased low-density lipoprotein cholesterol, and insulin resistance and DM. In an observational study of a population-based cohort of 73,196 people, the unadjusted rates per 1,000 person-years for developing incident diabetes was 29.0 for those receiving GnRH analogue therapy versus 20.9 for those not on treatment, with an adjusted hazard ratio of incident DM of 1.44 with GnRH analogues..$^{80} \mathrm{GnRH}$ analogue-induced hyperglycaemia has been reported to respond well to pioglitazone. ${ }^{81}$ Females also may develop worsening of glycaemic control when treated with these agents. ${ }^{22}$

\section{Mifepristone}

Mifepristone is a glucocorticoid receptor blocker acting on glucocorticoid receptor-II and the progesterone receptor. It is approved for treatment of hyperglycaemia in the setting of Cushing's syndrome. In a study of 50 patients with endogenous Cushing's syndrome (including pituitary, adrenal and ectopic causes of hypercortisolism), $60 \%$ of patients with glucose intolerance or DM showed improvement. In patients using insulin, their dose was reduced by half and mean $\mathrm{HDA} 1 \mathrm{C}$ came down from $7.43 \%$ at baseline to $6.29 \%$ at study conclusion. ${ }^{83}$ 


\section{Mecasermin}

Mecasermin or recombinant human IGF-1 is used for the treatment of growth failure resulting from severe primary IGF-1 deficiency, or in cases of $\mathrm{GH}$ gene deletion with neutralising antibodies to $\mathrm{GH}$ that make $\mathrm{GH}$ ineffective. ${ }^{84}$ Hypoglycaemia is a recognised side effect of mecasermin, especially in small children due to inconsistent oral intake. Individuals should not undertake high-risk activities (e.g. swimming) within 2-3 hours after dosing, particularly at the initiation of therapy until the dose is tolerated. It is injected subcutaneously twice daily and should be administered within 20 minutes of a meal or a snack.

\section{Effect of diabetes on hypophyseal function}

Pituitary hormones may be altered in both T1DM and T2DM.

\section{Diabetes and the growth hormone/insulin-like growth factor-1 axis \\ Type 1 diabetes mellitus}

$\mathrm{GH}$ and insulin appear to be metabolically antagonistic to each other, but in reality, insulin plays a permissive role in $\mathrm{GH}$ action. Portal insulin up-regulates hepatic GH-receptor expression, and that in turn causes downstream production of IGF-1 and IGF-binding protein-3 (IGFBP3). ${ }^{85}$ LoW portal insulin levels, decreased IGF-1 levels and elevated proinflammatory cytokines in T1DM lead to IGF-1 resistance. Low IGF-1 in T1DM has multiple deleterious effects like decreased growth, insulin resistance and poor CV outcomes..$^{86}$ The imbalance in the GH/IGF-1/IGFBP3 axis, however, does not get corrected with continuous subcutaneous insulin infusion despite optimal glycaemic control, but does improve with continuous portal insulin infusion. ${ }^{87,88}$ The implication of the finding, that even optimal glycaemic control might not restore the GH/IGF-1 axis is not clear. Whether deficient portal insulin in T1DM adversely affects the final height outcome is yet to be proven, and the adult height of individuals with T1DM remains highly variable. ${ }^{86}$

\section{Type 2 diabetes mellitus}

The GH/IGF-1 axis plays a possible role in glucose homeostasis and the etiopathogenesis of T2DM and insulin resistance. InT2DM, GH levels are low and free IGF-1 levels are elevated; however, total IGF-1 levels are normal. In addition, IGFBP1 and IGFBP2 levels are low, while IGFBP3 is elevated in T2DM. ${ }^{89}$ Epidemiological studies on the connection between IGF proteins and the incidence of T2DM report conflicting results and most fail to show any association..$^{90,91}$ Low levels of IGFBP1, however, have been associated with a future risk of T2DM development. ${ }^{92}$ Glucose metabolism and $\mathrm{GH}$, IGF-1 and IGFBPs are interlinked in a complicated manner and their relationship is a subject of ongoing research.

\section{Diabetes and the gonadal axis}

It is well established that males with T2DM have a high prevalence of decreased serum testosterone along with inappropriately low luteinising hormone and FSH levels, a condition that has been labelled as functional $\mathrm{HH}$ because it is not associated with any structural disease. ${ }^{25} \mathrm{HH}$ has a close link to insulin resistance and can be found in individuals with T2DM, obesity and metabolic syndrome. ${ }^{1,2} \mathrm{C}$-reactive protein levels are higher in individuals with $\mathrm{HH}$ and have an inverse association to testosterone levels. Inflammation secondary to insulin resistance may contribute to its pathogenesis.93 Testosterone replacement is recommended in symptomatic males with $\mathrm{HH}$, but there is controversy regarding the $\mathrm{CV}$ risk associated with testosterone therapy.94,95 An interesting observation is that the hypogonadism in these conditions responds well to clomiphene. ${ }^{96}$ The prevalence of $\mathrm{HH}$ in males with T1DM does not appear to be increased, and risk factors in T1DM for low testosterone levels are similar to that of the general population. ${ }^{97}$
Table 5: Syndromes involving the pituitary and diabetes/the pancreas

\begin{tabular}{|l|l|}
\hline Syndrome & Clinical manifestations \\
\hline Wolfram syndrome & $\begin{array}{l}\text { DM, central diabetes insipidus, optic atrophy, } \\
\text { sensorineural hearing loss, neurodegeneration, } \\
\text { prototype of endoplasmic reticulum disorder }\end{array}$ \\
\hline Prader-Willi syndrome & $\begin{array}{l}\text { Hyperphagia, obesity, hypotonia, } \\
\text { hypopituitarism, DM }\end{array}$ \\
\hline Mitochondrial diseases & $\begin{array}{l}\text { Maternal inheritance, DM (mimics T2DM), } \\
\text { sensorineural deafness (early onset), HPA axis } \\
\text { dysfunction, GH deficiency }\end{array}$ \\
\hline $\begin{array}{l}\text { Multiple endocrine neoplasia } \\
\text { syndrome 1 }\end{array}$ & $\begin{array}{l}\text { Parathyroid adenoma, pituitary tumours, } \\
\text { pancreatic endocrine tumour - gastrinoma and } \\
\text { insulinoma (small, multiple, early onset) }\end{array}$ \\
\hline
\end{tabular}

$D M=$ diabetes mellitus; $G H=$ growth hormone;

HPA = hypothalamus-pituitary-adrenal; T2DM = type 2 diabetes mellitus.

\section{Diabetes and prolactin secretion}

An early study reported that prolactin levels are elevated in T2DM. ${ }^{98}$ Subsequent findings, however, suggest that high prolactin levels reduce the prevalence of DM and insulin resistance. ${ }^{13,14}$ Additionally, a study reported that those with diabetic retinopathy have lower levels of prolactin. ${ }^{99} \mathrm{~A}$ possible hypothesis behind this is prolactin is broken down to vasoinhibins, with antiangiogenic, vasoconstrictive and anti-permeability effects that may exert protective action in diabetic retinopathy. ${ }^{100}$ However, a few other clinical studies have not confirmed the benefits of elevated levels of prolactin on retinopathy. ${ }^{101,102}$

\section{Diabetes and the cortisol axis}

Animal studies suggest that the hypothalamus-pituitary-adrenal (HPA) axis may be hyperfunctioning in T2DM and that these changes may be mediated through the endogenous cannabinoid receptor system. ${ }^{103-6}$ The clinical implication of this finding is not yet known.

\section{Diabetes and hypophysis with syndromic connection}

Diabetes is a defining feature of numerous syndromes and many of them have associated hypophyseal affection (Table 5).

\section{Wolfram syndrome}

Wolfram syndrome is a rare genetic disease which manifests as childhood-onset DM, central diabetes insipidus, optic nerve atrophy, sensorineural hearing loss and neurodegeneration. It is a prototype of endoplasmic reticulum disorder occurring due to mutation in the WFS1 gene and pancreatic beta cells, and neurons are particularly sensitive to it, most probably due to high rates of protein synthesis. ${ }^{107}$

\section{Prader-Willi syndrome}

Prader-Willi syndrome is one of the most common varieties of obesity syndrome. It results from the absence of expression of the paternally active genes on the long arm of chromosome 15. Excessive appetite, obesity and hypotonia are hallmarks of this syndrome. Hypopituitarism is often an accompanying feature with sequential loss of $\mathrm{GH}$, luteinising hormone, FSH, TSH and ACTH secretion. ${ }^{108}$

\section{Mitochondrial disease}

Another situation where diabetes and pituitary dysfunction coexist are mitochondrial disorders. The common variants of mitochondrial diseases include mitochondrial encephalomyopathy, lactic acidosis 
and stroke-like episodes (MELAS); maternally inherited diabetes and deafness; and Kearns-Sayre syndrome (KSS). Mitochondrial diabetes presents much like T2DM and should be suspected in the presence of early-onset sensorineural deafness along with maternal inheritance of either condition. Other features which suggest the possibility of mitochondrial diabetes are cardiomyopathy, seizure disorder, ptosis or unusual strokes. Impairment of the HPA axis occurs in severe mitochondrial phenotypes presenting in childhood and more commonly in MELAS and KSS. GH deficiency has been described in KSS. ${ }^{109}$

\section{Multiple endocrine neoplasia 1 syndrome}

Multiple endocrine neoplasia 1 (MEN1) syndrome is an autosomal dominant condition that is characterised by a predisposition to tumour formation in the parathyroid glands, anterior pituitary and islet cells of pancreas. Menin, a tumour suppressor gene located on the long arm of chromosome 11 (11q13), is inactivated in the majority of affected members. ${ }^{110}$ In a recently published series of patients with MEN1 syndrome, the prevalence of pituitary tumours was $42 \%$. Prolactinoma was the most common variety of pituitary tumour, followed by GH-secreting tumour, Cushing's disease, gonadotroph adenomas and clinically non-functioning tumours.111 The other manifestation of MEN1 syndrome is tumour of the pancreas and gastro-intestinal neuroendocrine glands. Zollinger-Ellison syndrome, or gastrinoma, is the most common presentation among that group, followed by insulinoma. Insulinomas in MEN1 syndrome are usually small, multiple and present early in the second to fourth decade. ${ }^{112}$

\section{Other syndromic associations}

There are multiple other syndromes, such as Bardet-Biedl syndrome, Friedreich ataxia, Alström syndrome and Berardinelli-Seip syndrome where diabetes and hypophyseal dysfunction coexist.

\section{Conclusion}

Pituitary hormones play an integral role in controlling glucose metabolism. There are diseases like acromegaly and Cushing's disease which are overtly associated with diabetes. Emerging evidence suggests that prolactin, vasopressin and oxytocin also exert a subtle physiological role in glucose homeostasis. ${ }^{15,29,41}$ The choice of medication in pituitary diseases such as acromegaly can be governed by the glycaemic impact of these drugs; pegvisomant being preferred in patients with uncontrolled hyperglycaemia, while pasireotide is often administered in those where glycaemic control is optimal. Bromocriptine quick-release formulation, a drug principally used for hyperprolactinaemia, has been used as an antihyperglycaemic agent and might open the door for future medications which target the CNS as a modality to treat DM. Diabetes is a recognised cause of $\mathrm{HH}$ in males, and inflammation associated with T2DM has a negative impact on functioning of gonadotrophs. ${ }^{1,2}$ Whether replacement of testosterone in these individuals is beneficial is again a subject of controversy. Finally, there are syndromes which link the pituitary and the pancreas, and which throw important light on the mechanism of secretory function of these two major endocrine glands. $\square$
Dandona P, Dhindsa S, Chaudhuri A, et al. Hypogonadatrophic hypogonadism in type 2 diabetes, obesity and the metabolic hypogonadism in type 2 diabetes, obesity

2. Dandona P, Dhindsa S, Chandel A, Chaudhuri A. Hypogonadotropic hypogonadism in men with type 2 diabetes Postgrad Med. 2009;121:45-51.

3. Cooper O, Geller JL, Melmed S. Ovarian hyperstimulation syndrome caused by an FSH-secreting pituitary adenoma. Nat Clin Pract Endocrinol Metab. 2008;4:234-8.

4. Petrossians P, Daly AF, Natchev E, et al. Acromegaly at diagnosis in 3173 patients from the Liège Acromegaly Survey (LAS) Database. Endocr Relat Cancer. 2017;24:505-18.

5. Ferraù F, Albani A, Ciresi A, et al. Diabetes secondary to acromegaly: physiopathology, clinical features and effects of treatment. Front Endocrinol. 2018:9:358

6. Ben-Shlomo A. Pituitary gland: predictors of acromegalyassociated mortality. Nat Rev Endocrinol. 2010;6:67-9.

Arosio M, Reimondo G, Malchiodi E, et al. Predictors of morbidity and mortality in acromegaly: an Italian survey. Eur J Endocrinol. 2012;167:189-98.

8. Barbot M, Ceccato F, Scaroni C. Diabetes mellitus secondary to Cushing's disease. Front Endocrinol (Lausanne). 2018;9:284.

9. Mazziotti G, Gazzaruso C, Giustina A. Diabetes in Cushing syndrome: basic and clinical aspects. Trends Endocrinol Metab. 2011;22:499-506.

10. Munir A, Newell-Price J. Management of diabetes mellitus in Cushing's syndrome. Neuroendocrinology. 2010;92(Suppl. 1):82-5.

11. American Diabetes Association. Diagnosis and classification of diabetes mellitus. Diabetes Care. 2014;37(Suppl. 1):S81-90

12. Pala NA, Laway BA, Misgar RA, Dar RA. Metabolic abnormalities in patients with prolactinoma: response to treatment with cabergoline. Diabetol Meta Syndr. 2015;7:99.

13. Serri $O$, Beauregard $H$, Rasio E, Hardy J. Decreased sensitivity to insulin in women with microprolactinomas. Fertil Steril. 1986;45:572-4

14. Wang T, Lu J, XU Y, et al. Circulating prolactin associates with diabetes and impaired glucose regulation: a population-based study. Diabetes Care. 2013;36:1974-80.

15. Daimon M, Kamba A, Murakami H, et al. Association between serum prolactin levels and insulin resistance in non-diabetic men. PLOS ONE. 2017;12:e0175204.

16. Sorenson RL, Brelje TC. Adaptation of islets of Langerhans to pregnancy: beta-cell growth, enhanced insulin secretion and the role of lactogenic hormones. Horm Metab Res. 1997;29:301-7.

17. Petryk A, Fleenor D, Driscoll P, Freemark M. Prolactin induction of insulin gene expression: the roles of glucose and glucose transporter-2 J Endocrinol 2000:164:277-86.

18. Sauvé D, Woodside B. Neuroanatomical specificity of prolactin-induced hyperphagia in virgin female rats. Brain Res. 2000;868:306-14.

19. Nilsson L, Binart N, Bohlooly-Y M, et al. Prolactin and growth hormone regulate adiponectin secretion and receptor expression in adipose tissue. Biochem Biophys Res Commun. 2005;331:1120-6.

20. Potenza M, Via MA, Yanagisawa RT. Excess thyroid hormone and carbohydrate metabolism. Endocr Pract. 2009:15:254-62.

21. Beck-Peccoz P, Persani L, Mannavola D, Campi I. Pituitary tumours: TSH-secreting adenomas. Best Pract Res Clin Endocrinol Metab. 2009:23:597-606.

22. Kumar N, Singh P, Kumar J, Dhanwal DK. Recurrent hypoglycaemia: a delayed presentation of Sheehan syndrome. BMJ Case Rep. 2014;2014:pii:bcr2013200991.

23. Haymond MW, Karl I, Weldon W, Pagliara AS. The role of growth hormone and cortisone on glucose and gluconeogenic substrate regulation in fasted hypopituitary children. J Clin Endocrinol Metab. 1976;42:846-56.

24. Jørgensen JO, Krag M, Jessen N, et al. Growth hormone and glucose homeostasis. Horm Res. 2004;62(Suppl. 3):51-5.

25. Grossmann M, Matsumoto AM. A perspective on middle-aged and older men with functional hypogonadism: focus on holistic management. J Clin Endocrinol Metab. 2017;102:1067-75

26. Simon D, Preziosi P, Barrett-Connor E, et al. Interrelation between plasma testosterone and plasma insulin in healthy adult men: the Telecom Study. Diabetologia. 1992:35:173-7.

27. Haffner SM, Karhapää P, Mykkänen L, Laakso M. Insulin resistance, body fat distribution, and sex hormones in men. Diabetes. 1994;43:212-9.

28. Mancini A, Raimondo S, Di Segni C, et al. Hypogonadism in metabolic syndrome: cause or consequence? Lesson from genetic hypogonadism and disorders of gender identity. J Endocrinol Diabetes Obes. 2014;2:1040.

29. Leng G, Sabatier N. Oxytocin - the sweet hormone? Trends Endocrinol Metab. 2017;28:365-76.

30. Ding C, Leow MK, Magkos F. Oxytocin in metabolic homeostasis: implications for obesity and diabetes management. Obes Rev. 2019;20:22-40.

31. Qian W, Zhu T, Tang B, et al. Decreased circulating levels of oxytocin in obesity and newly diagnosed type 2 diabetic patients I Clin Endocrinol Metab. 2014:99:4683-9.

32. Barengolts $\mathrm{E}$. Oxytocin - An emerging treatment for obesity and dysglycemia: review of randomized controlled trials and cohort studies. Endocr Pract. 2016;22:885-94.

33. Howl J, Ismail T, Strain AJ, et al. Characterization of the human liver vasopressin receptor. Profound differences between human and rat vasopressin-receptor-mediated responses suggest only a minor role for vasopressin in regulating human hepatic function. Biochem J. 1991;276:189-95.

34. Whitton PD, Rodrigues LM, Hems DA. Stimulation by vasopressin, angiotensin and oxytocin of gluconeogenesis in hepatocyte suspensions. Biochem J. 1978;176:893-8.

35. Abu-Basha EA, Yibchok-Anun S, Hsu WH. Glucose dependency of arginine vasopressin-induced insulin and glucagon release of arginine vasopressin-induced insulin and glucagon release
from the perfused rat pancreas. Metabolism. 2002;51:1184-90

36. Koshimizu TA, Nakamura K, Egashira N, et al. Vasopressin V1a and $\mathrm{V} 1 \mathrm{~b}$ receptors: from molecules to physiological systems. and V1b receptors: from molecul
Physiol Rev. 2012;92:1813-64.

37. Yibchok-anun S, Abu-Basha EA, Yao CY, et al. The role of arginine vasopressin in diabetes-associated increase in glucagon secretion. Regul Pept. 2004;122:157-62.

38. Cooper-Dehoff R, Cohen JD, Bakris GL, et al. Predictors of development of diabetes mellitus in patients with coronary artery disease taking antihypertensive medications (findings from the International Verapamil SR-Trandolapril Study [INVEST]). Am J Cardiol. 2006:98:890-4.

39. Enhörning S, Wang TJ, Nilsson PM, et al. Plasma copeptin and the risk of diabetes mellitus Circulation. 2010:121:2102-8.

40. Morgenthaler NG, Struck J, Alonso C, Bergmann A. Assay for the measurement of copeptin, a stable peptide derived from the precursor of vasopressin. Clin Chem. 2006;52:112-9.

41. Nakamura K, Velho G, Bouby N. Vasopressin and metabolic disorders: translation from experimental models to clinica use. J Int Med. 2017;282:298-309.

42. Roussel R, Fezeu L, Bouby N, et al. Low water intake and risk for new-onset hyperglycemia. Diabetes Care. 2011;34:2551-4.

43. Ciresi A, Giordano C. Glucose metabolism in children with growth hormone deficiency. Front Endocrinol. 2018:9:321.

44. Bell J, Parker KL, Swinford RD, et al. Long-term safety of recombinant human growth hormone in children. $J$ Clin Endocrinol Metab. 2010:95:167-77.

45. Allen DB, Backeljauw P, Bidlingmaier M, et al. GH safety workshop position paper: a critical appraisal of recombinant human GH therapy in children and adults. Eur J Endocrinol. 2015;174:P1-9.

46. Stochholm $\mathrm{K}$, Johannsson $\mathrm{G}$. Reviewing the safety of GH replacement therapy in adults. Growth Horm IGF Res 2015;25:149-57.

47. Luger A, Mattsson AF, Koltowska-Häggström M, et al. Incidence of diabetes mellitus and evolution of glucose parameters in growth hormone-deficient subjects during growth hormone replacement therapy: a long-term observational study. Diabetes Care. 2012;35:57-62.

48. Newman CB, Carmichael JD, Kleinberg DL. Effects of low dose versus high dose human growth hormone on body composition and lipids in adults with $\mathrm{GH}$ deficiency: a meta-analysis of placebo-controlled randomized trials. Pituitary. 2015;18:297-305.

49. Isgaard J, Arcopinto M, Karason K, Cittadini A. GH and the cardiovascular system: an update on a topic at heart. Endocrine. 2015;48:25-35

50. Gazzaruso C, Gola M, Karamouzis I, et al. Cardiovascular risk in adult patients with growth hormone (GH) deficiency and following substitution with $\mathrm{GH}$-an update. J Clin Endocrinol Metab. 2014;99:18-29

51. Alexopoulou O, Bex M, Kamenicky P, et al. Prevalence and risk factors of impaired glucose tolerance and diabetes mellitus at diagnosis of acromegaly: a study in 148 patients. Pituitary. 2014;17:81-89.

52. Cozzolino A, Feola T, Simonelli I, et al. Somatostatin analogs and glucose metabolism in acromegaly: a meta-analysis of prospective interventional studies. J Clin Endocrinol Metab. 2018;103:2089-99.

53. Giordano C Ciresi A, Amato MC, et al. Clinical and metabolic effects of first-line treatment with somatostatin analogues or surgery in acromegaly: a retrospective and comparative or surgery in acromegaly: a retrosper
study. Pituitary. 2012;15:539-51.

54. Giustina A, Mazziotti G, Cannavo S, et al. High-dose and high-frequency lanreotide autogel in acromegaly: a randomized, multicenter study. I Clin Endocrinol Metab. 2017;102:2454-64.

55. Caron PJ, Petersenn S, Houchard A, et al. Glucose and lipid levels with lanreotide autogel $120 \mathrm{mg}$ in treatment-naive patients with acromegaly: data from the PRIMARYS study. Clin Endocrinol. 2017:86:541-51.

56. van der Hoek J, van der Lelij AJ, Feelders RA, et al. The 
somatostatin analogue SOM230, compared with octreotide, induces differential effects in several metabolic pathways in acromegalic patients. Clin Endocrinol. 2005;63:176-84.

57. Gadelha MR, Bronstein MD, Brue T, et al. Pasireotide versus continued treatment with octreotide or lanreotide in patients with inadequately controlled acromegaly (PAOLA): a randomised, phase 3 trial. Lancet Diabetes Endocrinol. 2014;2:875-84.

58. Petersenn S, Salgado LR, Schopohl J, et al. Long-term treatment of Cushing's disease with pasireotide: 5 -year results from an open-label extension study of a Phase III trial. Endocrine. 2017; $57: 156-65$

59. Silverstein JM. Hyperglycemia induced by pasireotide in patients with Cushing's disease or acromegaly. Pituitary. 2016;19:536-43.

60. Kailey B, van de Bunt M, Cheley S, et al. SSTR2 is the functionally dominant somatostatin receptor in human pancreatic $\beta$ - and $\alpha$-cells. Am J Physiol Endocrinol Metab. 2012;303:E1107-16.

61. Henry RR, Ciaraldi TP, Armstrong D, et al. Hyperglycemia associated with pasireotide: results from a mechanistic study in healthy volunteers. I Clin Endocrinol Metab. 2013;98:3446-53.

62. Breitschaft A, Hu K, Hermosillo Resendiz K, et al. Management of hyperglycemia associated with pasireotide (SOM230): healthy volunteer study. Diabetes Res Clin Pract. 2014;103:458-65.

63. Trainer PJ, Drake WM, Katznelson L, et al. Treatment of acromegaly with pegvisomant, a growth hormone-receptor antagonist pegvisomant. N Eng/ J Med. 2000;342:1171-7.

64. Rose DR, Clemmons DR. Growth hormone receptor antagonist improves insulin resistance in acromegaly. Growth Horm IGF Res. 2002;12:418-24.

65. Parkinson C, Drake WM, Roberts ME, et al. A comparison of the effects of pegvisomant and octreotide on glucose, insulin, gastrin, cholecystokinin, and pancreatic polypeptide responses to oral glucose and a standard mixed meal. J Clin Endocrinol to oral glucose and a standard

66. Barkan AL, Burman P Clemmons DR, et al. Glucose homeostasis and safety in patients with acromegaly converted from long-acting octreotide to pegvisomant. I Clin Endocrinol Metab. 2005:90:5684-91.

67. Colao A, Arnaldi G, Beck-Peccoz P, et al. Pegvisomant in acromegaly: why, when, how. J Endocrinol Invest. 2007;30:693-9.

68. Droste M, Domberg J, Buchfelder M, et al. Therapy of acromegalic patients exacerbated by concomitant type 2 diabetes requires higher pegvisomant doses to normalise IGF-I levels. Eur J Endocrinol. 2014;171:59-68.

69. Neggers SJ, van der Lely AJ. Combination treatment with somatostatin analogues and PEG in acromegaly. Growth Horm IGF Res. 2011;21:129-33.

70. Melmed S, Bronstein MD, Chanson P, et al. A consensus statement on acromegaly therapeutic outcomes. Nat Rev Endocrinol 2018:14:552-61.

71. DeFronzo RA. From the triumvirate to the ominous octet: a new paradigm for the treatment of type 2 diabetes mellitus. Diabetes. 2009;58:773-95.

72. Tschoner A, Engl J, Laimer M, et al. Metabolic side effects of antipsychotic medication. Int I Clin Pract. 2007;61:1356-70.

73. DeFronzo RA. Bromocriptine: a sympatholytic, D2-dopamine agonist for the treatment of type 2 diabetes. Diabetes Care. 2011;34:789-94.

74. US Food and Drug Administration. Cycloset [bromocriptine] prescribing information. 2017. Available from: www.accessdata. fda. gov/drugsatfda docs/label/2017/020866s006s007lbl.pdf (accessed 15 October 2019).

75. Gaziano JM, Cincotta AH, O'Connor CM, et al. Randomized clinical trial of quick-release bromocriptine among patients with type 2 diabetes on overall safety and cardiovascular outcomes. Diabetes Care. 2010;33:1503-8.

76. Bahar A, Kashi Z, Daneshpour E, et al. Effects of cabergoline on blood glucose levels in type 2 diabetic patients: a double-blind controlled clinical trial. Medicine (Baltimore). 2016:95:e4818.

77. Korner J, LO J, Freda PU, Wardlaw SL. Treatment with cabergoline is associated with weight loss in patients with hyperprolactinemia. Obes Res. 2003;11:311-2.

78. Gibson CD, Karmally W, MCMahon DJ, et al. Randomized pilot study of cabergoline, a dopamine receptor agonist: effects on body weight and glucose tolerance in obese adults. Diabetes Obes Metab. 2012;14:335-40.

79. Manning PJ, Grattan D, Merriman T, et al. Pharmaceutical interventions for weight-loss maintenance: no effect from cabergoline. Int J Obes (Lond). 2018:42:1871-9.

80. Keating NL, O'Malley AJ, Smith MR. Diabetes and cardiovascula disease during androgen deprivation therapy for prostate cancer. I Clin Oncol. 2006;24:4448-56.

81. Inaba $\mathrm{M}$, Otani $\mathrm{Y}$, Nishimura $\mathrm{K}$, et al. Marked hyperglycemia after androgen-deprivation therapy for prostate cancer and after androgen-deprivation therapy for prostate cancer and
usefulness of pioglitazone for its treatment. Metabolism. usefulness of piog

82. Coddington $\mathrm{CC}$, Hassiakos DK, Harrison HC, et al. Effect of gonadotropin-releasing hormone analogue on the glucose metabolism in a diabetic patient. Gynecol Obstet Invest. 1990;30:246-8

83. Fleseriu M, Biller BM, Findling JW, et al. SEISMIC Study Investigators. Mifepristone, a glucocorticoid receptor antagonist, produces clinical and metabolic benefits in patients with Cushing's syndrome. J Clin Endocrinol Metab. 2012;97:2039-49.

84. Backeliauw PF, Underwood LE, GHIS Collaborative Group. Therapy for 6.5-7.5 years with recombinant insulin-like growth factor I in children with growth hormone insensitivity syndrome: a clinical research center study syndrome. $J$ Clin Endocrinol Metab. 2001:86:1504-10.

85. Leung KC, Doyle N, Ballesteros M, et al. Insulin regulation of human hepatic growth hormone receptors: divergent effects on biosynthesis and surface translocation. J Clin Endocrino Metab. 2000;85:4712-20.

86. Nambam B, Schatz D. Growth hormone and insulin-like growth factor-l axis in type 1 diabetes. Growth Horm IGF Res. 2018;38:49-52.

87. Hedman CA, Frystyk J, Lindström T, et al. Intraperitoneal insulin delivery to patients with type 1 diabetes results in higher serum IGF-I bioactivity than continuous subcutaneous insulin infusion. Clin Endocrinol. 2014;81:58-62.

88. van Dijk PR, Logtenberg SJ, Chisalita SI, et al. Different effects of intraperitoneal and subcutaneous insulin administration on the GH-IGF-1 axis in type 1 diabetes. I Clin Endocrinol Metab. the GH-IGF-1 axis in

89. Raipathak SN, Gunter MJ, Wylie-Rosett J, et al. The role of insulin-like growth factor- and its binding proteins in glucose homeostasis and type 2 diabetes. Diabetes Metab Res Rev. 2009;25:3-12.

90. Rajpathak SN, He M, Sun Q, et al. Insulin-like growth factor axis and risk of type 2 diabetes in women. Diabetes. 2012;61:2248-54

91. Schneider HJ, Friedrich N, Klotsche J, et al. Prediction of incident diabetes mellitus by baseline IGF1 levels. Eur J Endocrinol. 2011:164:223-9.

92. Petersson U, Ostgren CJ, Brudin L, et al. Low levels of insulin-like growth-factor-binding protein-1 (IGFBP-1) are prospectively associated with the incidence of typ 2 diabetes and impaired glucose tolerance (IGT): the
Söderåkra Cardiovascular Risk Factor Study. Diabetes Metab. 2009:35:198-205.

93. Kupelian V, Chiu GR, Araujo AB, et al. Association of sex hormones and $\mathrm{C}$-reactive protein levels in men. Clin Endocrinol (OXf). 2010;72:527-33.

94. Vigen $\mathrm{R}$ O'Donnell $\mathrm{Cl}$ Barón $\mathrm{AE}$, et al Association of testosterone therapy with mortality, myocardial infarction, and stroke in men with low testosterone levels. JAMA. 2013;310:1829-36.

95. Anawalt BD, Yeap BB. Conclusions about testosterone therapy and cardiovascular risk. Asian J Androl. 2018;20:152-3.

96. Pelusi C, Giagulli VA, Baccini M, et al. Clomiphene citrate effect in obese men with low serum testosterone treated with metformin due to dysmetabolic disorders: a randomized, double-blind, placebo-controlled study. PLOS One. 2017; 12:e0183369.

97. Holt SK, Lopushnyan N, Hotaling J, et al. Prevalence of low testosterone and predisposing risk factors in men with type 1 diabetes mellitus: findings from the DCCT/EDIC. J Clin Endocrinol Metab. 2014:99:E1655-60.

98. Mooradian AD, Morley JE, Billington CJ, et al. Hyperprolactinaemia in male diabetics. Postgrad Med $\rfloor$. 1985;61:11-4

99. Arnold E, Rivera JC, Thebault S, et al. High levels of serum prolactin protect against diabetic retinopathy by increasing ocular vasoinhibins. Diabetes. 2010;59:3192-7.

100. Triebel J, Macotela Y, de la Escalera GM, Clapp C. Prolactin and vasoinhibins: endogenous players in diabetic retinopathy. IUBMB Life. 2011;63:806-10.

101. Mooradian AD, Morley J E, Billington $\mathrm{CJ}$, et al. Hyperprolactinaemia in male diabetics. Postgrad Med 1985;61:11-14.

102. Shokoofeh B, Nasser S, Abrishami M, Haleh R. Serum prolactin level and diabetic retinopathy in type 2 diabetes. J Diabetes Metab. 2012:3:173.

103. Luo Q Chen S, Deng J, et al. Endocannabinoid hydrolase and cannabinoid receptor 1 are involved in the regulation of hypothalamus-pituitary-adrenal axis in type 2 diabetes. Metab Brain Dis. 2018:33:1483-92.

104. Noguchi S, Ohno Y, Aoki N. Adrenocortical insufficiency in Otsuka long-Evans Tokushima fatty rats, a type 2 diabetes mellitus model. Metabolism. 2007;56:1326-33.

105. Gong L, Zeng $W$, Yang Z, et al. Comparison of the clinical manifestations of type 2 diabetes mellitus between rhesus monkey (Macaca mulatta lasiotis) and human being. Pancreas. 2013;42:537-42

106. Hansen B. Investigation and treatment of type 2 diabetes in nonhuman primates. Meth Mol Biol. 2012;933:177-85.

107. Urano F. Wolfram syndrome: diagnosis, management, and treatment. Curr Diab Rep. 2016;16:6

108. Cataletto M, Angulo M, Hertz G, Whitman B. Prader-Willi syndrome: a primer for clinicians. Int J Pediatr Endocrinol. 2011;2011:12.

109. Schaefer AM, Walker M, Turnbull DM, Taylor RW. Endocrine disorders in mitochondrial disease. Mol Cell Endocrinol. 2013;379:2-11

110. Agarwal SK, Lee Burns A, Sukhodolets KE, et al. Molecular pathology of the MEN1 gene. Ann N Y Acad Sci. 2004;1014:189-98

111. Vergès $B$, Boureille $F$, Goudet $P$, et al. Pituitary disease in MEN type 1 (MEN1): data from the France-Belgium MEN1 multicenter study. J Clin Endocrinol Metab. 2002;87:457-65.

112. Pipeleers-Marichal M, Somers $G$, Willems $G$, et al. Gastrinomas in the duodenums of patients with multiple endocrine neoplasia type 1 and the Zollinger-Ellison syndrome. N Eng/ J Med. 1990:322:723-7. 